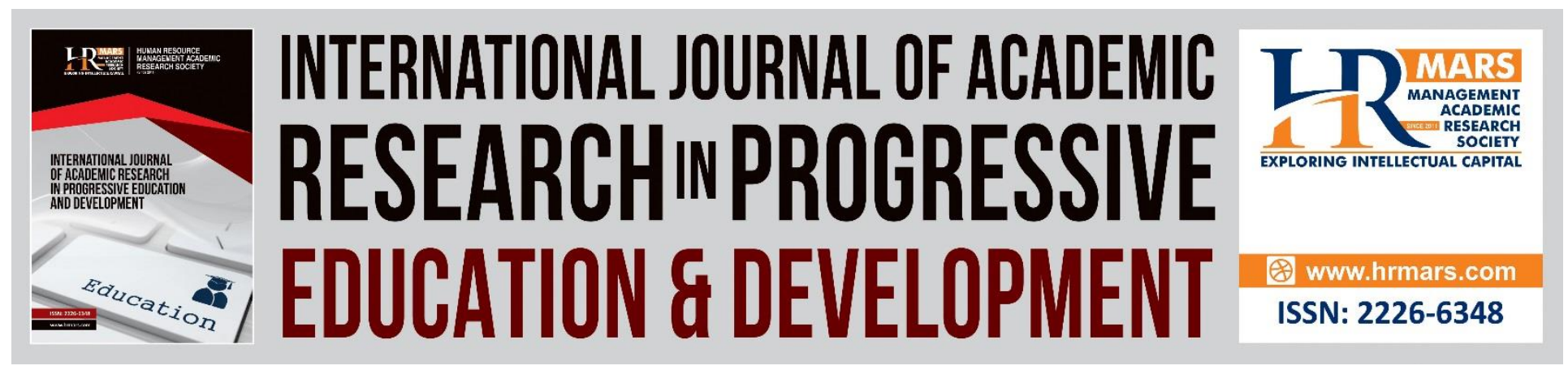

\title{
Enhancing English Language Learning and Teaching via Qgram (Telegram and Quizlet) Innovation
}

\author{
Muhammad Nafis Bin Azman, Faridza binti Mohd Shuraimi, \\ Melor binti Md Yunus
}

To Link this Article: http://dx.doi.org/10.6007/IJARPED/v7-i4/5344

DOI: $10.6007 /$ IJARPED/v7-i4/5344

Received: 21 Oct 2018, Revised: 17 Nov 2018, Accepted: 27 Nov 2018

Published Online: 10 Dec 2018

In-Text Citation: (Azman, Shuraimi, \& Yunus, 2018)

To Cite this Article: Azman, M. N. Bin, Shuraimi, F. binti M., \& Yunus, M. binti M. (2018). Enhancing English Language Learning and Teaching via Qgram (Telegram and Quizlet) Innovation. International Journal of Academic Research in Progressive Education and Development, 7(4), 435-446.

Copyright: (C) 2018 The Author(s)

Published by Human Resource Management Academic Research Society (www.hrmars.com)

This article is published under the Creative Commons Attribution (CC BY 4.0) license. Anyone may reproduce, distribute, translate and create derivative works of this article (for both commercial and non-commercial purposes), subject to full attribution to the original publication and authors. The full terms of this license may be seen at: http://creativecommons.org/licences/by/4.0/legalcode

Vol. 7, No. 4, 2018, Pg. 435 - 446

http://hrmars.com/index.php/pages/detail/IJARPED

JOURNAL HOMEPAGE

Full Terms \& Conditions of access and use can be found at http://hrmars.com/index.php/pages/detail/publication-ethics 


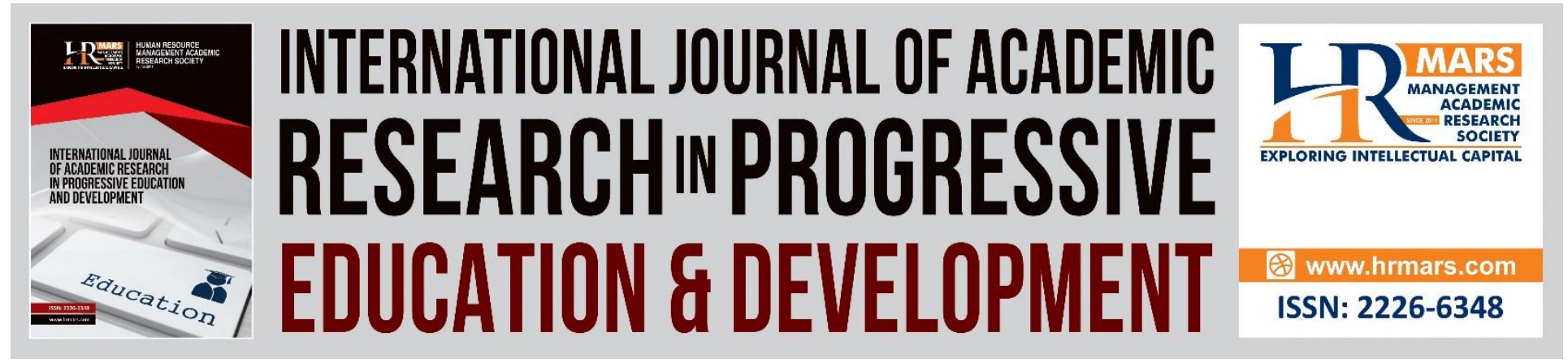

\title{
Enhancing English Language Learning and Teaching via Qgram (Telegram and Quizlet) Innovation
}

\author{
Muhammad Nafis Bin Azman \\ Research Scholar, Universiti Kebangsaan Malaysia \\ Email:muhammadnafisazman@yahoo.com \\ Faridza binti Mohd Shuraimi \\ Research Scholar, Universiti Kebangsaan Malaysia \\ Email: ms.faridza@gmail.com \\ Melor binti Md Yunus \\ Corresponding Author, Universiti Kebangsaan Malaysia \\ Email:melor@ukm.edu.my
}

\begin{abstract}
Technology has become widespread in our life and also the life our learners. Hence, it is extremely crucial to integrate the use of technology in language teaching and learning as it is aligned to one of 21st century learning elements. The current English language lessons are mostly merely on recalling facts of the texts and conventional that leads to the issue of students' lack of interest in learning English language. Therefore, the aim of this study was to enhance students' interests in English language teaching and learning by using Qgram that creates interactive, differentiated and feasible learning platform that fits different learners' learning styles. Hence, Qgram combines the use of Telegram and Quizlet which provides learners with a better and interesting learning platform precisely for English language learning. So, fifty Form 5 students were selected from two secondary schools in Kluang, Johor and Petaling Perdana, Selangor. An action research using McNiff model was conducted throughout a 4-week of reading and grammar lessons. The students were exposed to having instructions and discussions in Telegram and doing exercises in Quizlet application. Interview and observations on the participations of students in both Telegram and Quizlet were conducted to view students' perceptions on this Qgram innovation. The finding echoed that learners enjoyed using Qgram innovation in English teaching and learning as they found Telegram and Qgram were interesting, feasible and interactive. Qgram offers a new dimension of English language learning that utilises both Telegram and Quizlet applications which create more interesting and fulfilling learning mediums that suit with the
\end{abstract}


INTERNATIONAL JOURNAL OF ACADEMIC RESEARCH IN PROGRESSIVE EDUCATION AND

DEVELOPMENT

Vol. 7, No. 4, 2018, E-ISSN: 2226-6348 @ 2018 HRMARS

needs of 21st-century students. In short, applications like Telegram and Quizlet should be fully utilized its use to the maximum, so teaching and learning will be more engaging.

Keywords: Learner's interest, interactive, Telegram, Quizlet, MALL, CALL.

\section{Introduction}

Integration of technology into teaching and learning English language is getting common these days and getting positive impacts by both teachers and learners in its implementation all over the world. As 21st century has approached our life, it is without doubt that technology has an important role in language teaching and learning. Mona (2017), mentioned that it is undeniable that the current generation that we teach nowadays are the generation of technology and they are actively attached to their digital gadgets. Furthermore, Andrea (2014) stated that in this new technology era, learners should be provided with attractive contents in social media platform such as Telegram. Somano (2014) have emphasised on this matter as he stated that digital tools like Facebook, Twitter, Youtube, Telegram and Skype are efficient in creating affective communication among learners. He further explained on how the usage of social media has also improved the comprehension of the contents as the learners start to develop selfmotivation which indirectly would enhance English Language teaching and learning. In second language learning, Li (2017) proposed that the crucial role of social media should not be taken for granted. However, in some schools and even higher institutions in Malaysia, English language teaching and learning is still undergoing the conventional chalk and talk methodology. According to Ganapathy, Shuib, \& Azizan, n.d.(2016) mostly English language classrooms in Malaysia are still portraying traditional and conventional pedagogical strategies and it makes the lesson become uninteresting and dull. Still, teachers in most schools in Malaysia face difficulty in sustaining the interest of learners precisely in English language classroom which is due to the lack of differentiated, interactive and feasible learning platforms. Mona (2017) stated that using conventional methods in teaching this alpha generation will create a huge gap between what the teachers bring to the class and what are expected by the students. Due to that matter, the innovation of Qgram is meant to feed learners' preferences on technological learning mediums as it applies simple applications of Quizlet and Telegram. Hence, Telegram and Quizlet are considered as the one of the best combination of applications to be applied in English language learning as the combination embraces the positive elements of the technology applications and provides better learning environment for learners especially young learners. Therefore, the objective of this study was to enhance students' interests in English language teaching and learning by using Qgram which creates interactive, differentiated and feasible learning platform that fits different learners' learning styles.

\section{Conventional Language Learning}

Conventionally, teachers spend most the times explaining the meanings of tons of words and the efforts seem pointless because it still has not solved the main issue of the students. Some teachers are also still abiding to the old-fashioned methods on drilling method where students jot down the information into books and just focusing on memorizing. There is no fun and feasible element which allows learners to retain their memory longer and expand their attention span to the lesson. Che Musa, Lie and Azman (2012) highlighted similar idea in their research as learners are seen to need ample support, be it in terms of support or providing learning environment 
DEVELOPMENT

Vol. 7, No. 4, 2018, E-ISSN: 2226-6348 ๑ 2018 HRMARS

which is meaningful in assisting them to instil interest in English. This is related to a statement found in Che Mat and Yunus (2014) where they emphasised that having positive attitude in learning will show significant contribution towards the excel of second language learning. Normally, teachers are expected to do the analysis and discussions and students will just absorb everything from the teachers as Zubaidah and Shaidatul (2010), stated in which Malaysian students especially those who were from the rural areas tend to be the passive listeners and expected to receive as much input as they could from teachers instead of being an "active provider". Zubaidah and Shaidatul (2010) highlighted another that classroom practices and experiences can lead to frustration and develop negative perceptions towards English language learning and could be demotivating. Nagayar, Azian and Mangala (2015) highlighted in their study that there is a high possibility that literary texts are taught in the classroom just to prepare students for examination. So, Qgram innovation should be taken into an account as one of the feasible and interactive applications, in preparing learners for the examinations too. According to Neil (2016) there are many manifold online sources or materials that learners can access to which actually help to retain their information and make attention span longer.

\section{Mobile Assisted in Language Learning (MALL)}

A big bulky desktop or laptop are no longer relevant to our learners. Computers are not mobilized and it is not convenient as learners' engagement ends when they are away from the computer. That is why according to Yagmur and Zeynep (2017) and Gilbert (2017), mentioned that the conventional Computer Assisted Language Learning (CALL) activities are less flexible and immobilized, in compared to MALL. Md Yunus and Suliman (2014) highlighted that ICT had been seen to be assisting the learners to maximise their creativity as materials are available online to fit the learners' versatility. Hence, it can practice autonomous and creative learning if it was to be implemented in teaching and learning language. This has shown a significant purpose of utilizing ICT into teaching and learning language. Therefore, this study will explore the use of Qgram (Telegram and Quizlet). This Qgram innovation is mobile because it can be used in either smartphones or tablets. A study by Yagmur and Zeynep (2017) highlighted on an experimental group that showed an observed improvement on their post-test after they went through vocabulary intervention by using Quizlet flashcards as the learning tool. The study is the proof that MALL is actually one the most interactive and feasible approaches in improving learners' performances in learning second language (L2) and at the same time boost their motivation and interests in acquiring L2 skills. Digital tools such as Quizlet actually provides personalized learning styles than the conventional CALL leaning styles because it has the potential to afford learners towards having more flexibility (Gilbert, 2017). This is supported by another study by Zaki and Yunus (2015) in which indicated MALL to be having unique element of providing accessibility to the users to be having unlimited access everywhere they are. By doing so, it could encourage learners to have the interest of continuing language learning process with their own effort and become effective autonomous learner.

\section{Learners' Interest}

Interest has the power to determine someone's motivation in doing something in his or her life. In accordance to that, our learners' interest should be enhanced in learning English language because learning language requires learners to absorb large amount of input 


\section{INTERNATIONAL JOURNAL OF ACADEMIC RESEARCH IN PROGRESSIVE EDUCATION AND DEVELOPMENT \\ Vol. 7, No. 4, 2018, E-ISSN: 2226-6348 ๑ 2018 HRMARS}

(Xodabande, 2018). English language is one of the important languages extensively used around the world. It is vital for teachers not only to teach but able to stimulate students' interest in each lesson. Learning English as a second language has always been among one of the hardest subjects and due to the difficulties in learning, learners might lose their interests easily (Amjah, 2014). Interest is one of the strongest motivations for learning English. In addition, Xobande (2018) also mentioned that if properly used, technological innovations like social media and mobile applications will be able to enhance learners' interests and motivation as it scaffolds learners to have access to the target language input. Furthermore, the use of social media and mobile application is able to enhance learner's interests because this alpha generation is closely attached to technology around them such as their smartphones. So, according to Betser and Brand (2013), many of present learners are visual learners as technology has become the integral part of their lives and without technology, learners may not be able to learn effectively. It is important for teachers and educators to cater to this important needs of the learners as according to Lie and Yunus (2018), education begins with engagement. So using Qgram perhaps caters this alpha generation's interests on mobile application and strong engagement to their smart phones will hopefully enhance their interests in English language learning.

\section{Feasibility}

Telegram is a widely known communicative application that been used by different ranges of users. Yinka and Queendarline (2018) defined Telegram as a mobile application which enables people to communicate by using either mobile phones, tablets or computers. Its friendly and easy-access traits have made it among a popular communicative application that been used as compared to the competitor, Whatsapp, Telegram has additional traits of transferring and receiving documents and files without needing to store it into the device being used and also not taking our device storage. This is being supported by Yinka and Queendarline (2018) where they highlighted that the contents and files in Telegram are stored in Cloud. Hence, larger files transfer could be done at ease in compared to the other applications. Apart of its free accessibility, it is indeed a great platform to be used both by teachers and learners. Heba (2015) further explained on its advantage of providing high security as it is using encryption technique in setting the privacy and security. In addition to that, it also does not include any advertisement that could cause interference in having effective communication. In accordance to the stated descriptions of Telegram, it has offered an effective medium to be used in ESL classroom as it can suit both teachers' and learners' usage practicality. Quizlet on the other hand, is another favourite application to be used among educators. In a current study by Jackson III (2015), he mentioned that Quizlet is chosen among the preferred one over the other educational application like Educreations, which is another mobile application that enables educators to create instructional videos and share them to the university students in the United Arab Emirates. There are three main advantages of Quizlet that emphasised by Jackson III (2015) which are, having the ability to give grades and marks after completion of each activity, games-based and the availability of translation to L1. In accordance to the reasons above, Fischer (2012) highlighted the main benefit of using Quizlet as it enables the learners to reach flexibility and variability in online environments. It is essential for the educators to think in the time of technological era and consider how flexible it could be in applying mobile learning technologies (Ibrahim, Yusoff and 
INTERNATIONAL JOURNAL OF ACADEMIC RESEARCH IN PROGRESSIVE EDUCATION AND DEVELOPMENT

Vol. 7, No. 4, 2018, E-ISSN: 2226-6348 @ 2018 HRMARS

Kamaruddin, 2016) as how Quizlet and Telegram could provide when they are implemented in lessons.

\section{Differentiated and Interactive Learning}

In determining learners to get the effective second language learning environment, one should have included providing opportunities for the learners to interact and negotiate meaning, having authentic interaction using the targeted language, providing encouragement and exposure and facilitating the process (Hashim, Yunus and Embi, 2016). Denysiuk, Plavutska and Fedak (2018) labelled Telegram to be a learner-centered method where learners have unlimited access to information without limiting their usage within the classroom. By doing so, peers and teachers interactions among users can be maximized and promotes learning even more, in compared to be in traditional classroom. This is indeed an important element in English teaching and learning environment in which having high level of interactions and communication could really enhance the development of teaching and learning English language. Quizlet has also offered similarity on providing differentiated learning to the learners as Sanosi (2018) highlighted in his study that Quizlet users could have more options of learning as each mode of sets is available for the users to choose according to their preferences.

\section{Research Design}

The research design adopted in this study was action research, Jean Mcniff's Model (1988). An action research is among numerous research designs which is commonly used in education field. Action research design was chosen because it allowed the researchers as teachers to see whether Qgram innovation has any impact on learners' motivation or interest in English Language learning.

\section{Participants}

This action research was carried out in two secondary schools in Selangor and Johor. The first school was located in the urban area of Subang Jaya in Petaling Perdana district and the second school was located in the outskirt area of Kluang district. The participants of the action research were 50 students from two Form Five classes and all of the participants were similar in terms of English proficiency level.

\section{Research Procedure}

The action research was done for 4 weeks and these participants underwent 4 weeks of reading poetry and grammar lessons as Telegram and Quizlet were used for the medium of instruction. In each week, the participants were given notes or videos on the specific topics on poetry on Telegram. The discussion was held in Telegram before the teachers send Quizlet links to the Telegram group. The participants did the exercises in Quizlet and share their results by sending them to their Telegram group. Another discussion would be done to reflect on the errors done by the participants.

\section{Data Collection and Analysis}

The data were collected by a group semi-structured interview session with the students after the 4-week lessons with Qgram was done to see how Qgram can enhance English teaching 
DEVELOPMENT

Vol. 7, No. 4, 2018, E-ISSN: 2226-6348 @ 2018 HRMARS

and learning. The interview data were transcribed and analysed. The main themes of each transcript along with the experience and insight of each participants were extracted and analysed after intensive reading of each manuscript of the group interview. Another instrument used to see how Qgram can enhance English teaching and learning and support the interview finding was through observation. The observation was done before and after the use of Qgram on the 4-week lessons to find out the difference of their responses to the completion of the practices given in Quizlet and also their participation in Telegram classroom discussion. The data were not only analysed but the data were also being compared from one manuscript to another.

\section{Result}

A group semi-structure interview Learner's Responses towards the use of QGRAM Innovation Feasibility

Based on the group interview done with all of the participants in School A and School B, all 5 groups stated that Telegram feasibly allowed them to extend their classroom discussions among their group members without having to go for extra classes. A few participants mentioned they prefer to have to participate in Qgram activities rather than attending extra classes. Quoted from one of the learners, Syukri from the school in Subang Jaya,

"I think I like to do my exercises at home rather than coming to school. I feel more comfortable at home

Moreover, they also responded that they enjoyed Telegram and Quizlet because they could just simply do the tasks and discussions wherever they want. In School B, 16 of the participants stay at least 5 to 6 kilometres away from school. They explained to the interviewer that it is a major issue for them to go for school for extra classes since most of their parents are working parents. They pointed out at doing Qgram innovation has helped them to overcome that problem. Mohd Alif and Widiya from the school in Kluang pointed out,

"I live in Macap and it is almost 10km from school. It is a big issue for me to come for an extra class since my parents are working. So, through Telegram and Quizlet, I can still gain knowledge at home"

There was an interesting and significant point of view pointed out by the first and the third interview group, which they loved Telegram because it is feasible and it does not take up their data storage. It was specifically mentioned by Sawaludin from the school in Kluang,

"I don't have to worry my phone memory because Telegram saves all the screenshot, documents and videos in the cloud file"

\section{Learners' Interest}

Another issue that was asked to the participants was whether they thought Qgram lessons were interesting. During the interview, each interview group came into one agreement that Qgram was interesting because it allows them to have fun and at the same time improve 
INTERNATIONAL JOURNAL OF ACADEMIC RESEARCH IN PROGRESSIVE EDUCATION AND

DEVELOPMENT

Vol. 7, No. 4, 2018, E-ISSN: 2226-6348 ๑ 2018 HRMARS

their vocabulary and poetry understanding. Alif Ikmal from the school in Subang Jaya, specifically stated that,

"We stay in the hostel, so Qgram gives us the joy because it is like a game and we can compete with one another"

The participants from interview groups explained that, they can always redo the exercises in Quizlet as many times they want by just using through their smartphones. It helps them to retain the information or the vocabulary better than doing the exercises in their books which take more time to write. Chong from the school in Subang Jaya mentioned that,

"It is really difficult flip through the book every time I need the information, with Quizlet and Telegram I can just use my phone even when I am listening to song. It is fun and helpful"

\section{Differentiated and Interactive Learning Platform}

Another important finding that was derived from the interview was the participants value the idea of Quizlet allowing them to choose a few methods in doing the practices such multiplechoice question answers, mix-match, flashcards and written answer. They can opt from choosing the easiest methods (mix-match) to the toughest one (question answers). Out of 50 participants, 30 of them pointed out that Telegram helps them to learn in a very relax and fun environment. Quoted from 2 of the students, Mohd Iqmal and Teh from the schools in Kluang and Subang Jaya,

"I like doing mix-match because it is easy and fun. When I am confident with the content, I will do more challenging tasks"

"I think multiple-choice question is good because it is more challenging but if I want to have fun I will choose mix-match"

They informed the interviewer, they felt much comfortable and confident to be involved in the Telegram classroom discussion because they could see everyone made mistakes there. It was also mentioned during the interview that Quizlet gives them rooms to improve from one level to another level through the exercises method mentioned above. Nur Ain Iliyana from the school in Kluang stated that,

"I think like Telegram and Quizlet because when I ask questions or give answers, people cannot see me and we can see my friends make mistakes too"

\section{Observation finding before the use of Qgram Innovation}

The finding from the observation in the Telegram discussion resonated students' interest in completing the tasks when teachers posted them in Quizlet was very low. The finding from pre-observation (before Qgram innovation was run) showed most of the students had difficulty and reluctance to do the exercises in work books and submit to the teachers on time. It would be 2 to 3 days delay of submission and 15 learners failed to submit the work even after the submission date postponed. It reflected how English lesson can be dull and it affected their motivation to do the tasks. Another issue noted from the finding was the students had difficulty 
DEVELOPMENT

Vol. 7, No. 4, 2018, E-ISSN: 2226-6348 ๑ 2018 HRMARS

to recall the meanings of the words and the important notes on the poems. Some exercises were left empty without any attempt to answer the questions especially when it came to poetry questions. One of the reasons was due to their reluctance to refer back to the book and redo the exercises. The researchers also identified during the classroom discussion, students from both classes were very irresponsive. They tend to be very quiet and waited for teachers to spoon feed them. This might be due to the lack of confidence to point out opinions and questions.

\section{Observation finding after the use of Qgram Innovation}

After Qgram innovation was implemented, the finding echoes positive response from the students when completing the tasks given. Firstly, the frequency of students who completed the tasks on time showed a positive increment. On the first exercise, 47 students responded and completed the exercise right after the link was sent to the Telegram group. It was observed that some students did the exercise more than twice just to compete with their classmates. In fact, active participation by the students in the Telegram classroom discussions has shown another good impact on the learners' learning process. This portrays how learners' motivation in English Language learning has been enhanced by the use of Qgram. In addition to that, students showed the courage to ask teachers questions related to the exercise or notes and there are 10 advance students who managed to help their friends through Telegram classroom discussion. Those 10 students were seen being actively participative during the classroom discussion after 3 weeks of Qgram innovation implemented. They were able to sufficiently explain what they have done and discussed on the Telegram with the class. However, another 40 students showed only slight improvement in their participation in the classroom. Perhaps, if Qgram innovation is to be continued after the 4 weeks, the improvement will show major increment.

\section{Discussion}

The finding yielded from the study showed that Telegram and Quizzlet successfully enhance learners' interest in English language teaching and learning in both school. The results yielded from this study was supported by a study done by Yagmur and Zynep (2017). In his study, Yagmur and Zynep (2017) stated that using Quizlet as a platform to learn vocabulary lead to a better retention and learning outcomes. . Another perception that the students illustrated from the findings is Qgram has boosted their level of interest in giving their opinions during English language teaching and learning sessions and provided personalized mediums to grasp the knowledge without having to worry on making mistakes. This perhaps portrays that mobileassisted language learning like Qgram allows better and longer grasp of the information. Another study on the use of application in mobile phone specifically Quizlet by Gilbert (2017) also resonates the same result in which their lesson was sent as text SMS message like Telegram and their null hypothesis was rejected because SMS text message had a very positive impact on the vocabulary of the experimental group. Another study that supports the finding of this study is a study done Xodabande (2017). The study investigated the effectiveness of Telegram in teaching pronunciation to 30 Iranian EFL learners. After four weeks of treatment by using Telegram, it was found that there was significant improvement on the pronunciation of experiment group compared to the control and after delayed test done, no significant improvement was detected. This shows that social networking application like Telegram also has its own positive impact on the enhancement of English language teaching and learning. Zaki and Yunus (2015) mentioned 


\section{INTERNATIONAL JOURNAL OF ACADEMIC RESEARCH IN PROGRESSIVE EDUCATION AND}

DEVELOPMENT

Vol. 7, No. 4, 2018, E-ISSN: 2226-6348 @ 2018 HRMARS

that mobile learning promotes interactivity as it provides learners with medium of interaction with each other without perturbing of the distance by using different applications. Perchance, if Qgram innovation is to be continued after the 4 weeks, the improvement will show major increment.

Furthermore, the result echoed the finding from the study done by Farid and Niloofar (2017) which stated that online learning encourages independent and collaborative learning. Qgram innovation also provides students immediate feedbacks and it indirectly lessens the burden of teachers to mark and check students' works. Thus, it provides ample time for in-depth discussions in Telegram. The discussion done in Telegram is the evidence on how interactive Qgram innovation is. As mentioned in the previous subtopic, students found themselves more comfortable to discuss in Telegram and this actually supports the findings of Farid and Niloofar (2017) as they mentioned mobile-based learning (particularly Telegram) is very interactive as results showed the evidence of positive effects of Telegram on the learners' vocabulary learning abilities.

\section{Conclusion}

The major finding of this study also resonated how Qgram innovation managed elevate English language teaching and learning to be more interactive, feasible and fun. Hence, it is crucial for teachers to put high priority on learners' interests and learning preferences in selecting the best educational tools in teaching and learning. If applications like Telegram and Quizlet are utilized its use to the maximum, teaching and learning will be more engaging, interactive, feasible, and inspiring as according to Lie and Yunus (2018), learning starts with engagement. In addition, Qgram innovation indirectly lessens teachers' workload as Quizlet automatically generates the result for students to review with the teachers. In addition, this innovation gives teachers more contact hours with the students in Telegram in a very feasible, interactive, interesting and less-stressed medium. Lie and Yunus (2018) support the idea of all educators should clinch to authentic materials to help our students to enhance their English language skills outside of the classroom.

\section{REFERENCES}

Amjah, D. Y. P. H. (2014). A Study of Teachers' Strategies so Develop Students' Interest towards Learning English as a Second Language. Procedia - Social and Behavioral Sciences, 134, 188192. https://doi.org/10.1016/j.sbspro.2014.04.238

Andrea (2014). Learning English in the Social Media: A Resource to Keep Learning Outside the Classroom. [https://www.researchgate.net/publication/266853314]

Che Mat S.S. and Yunus M.M. (2014). Attitudes and Motivation Towards Learning English among FELDA School Students. Aust. J. Basic\& Appl. Sci, 8(5): 1-8, 2014. [https://pdfs.semanticscholar.org/7cab/0f400c1c7ff07d53045c40c8153c47c7ea15.pdf]

Che Musa N., Lie K.Y. and Azman H. (2012). Exploring English Language Learning and Teaching in 


\section{INTERNATIONAL JOURNAL OF ACADEMIC RESEARCH IN PROGRESSIVE EDUCATION AND}

\section{DEVELOPMENT}

Vol. 7, No. 4, 2018, E-ISSN: 2226-6348 @ 2018 HRMARS

Malaysia. GEMA Online Journal of Language Studies, 12: 33-51.[ https://www.researchgate.net/publication/287006835_Exploring_English_Language_Learning _And_Teaching_In_Malaysia]

Denis, G. (2017). 21 Reasons Why You Should Abandon Whatsapp and Start Using Telegram. [https://www.spicytechs.com.ng.21-reasons-ab]

Ganapathy, M., Shuib, M, \& Azizan, S. N. (2016). Malaysian ESL students' perceptions on the usability of a mobile application for grammar test: A case study of ESL undergraduates in universiti sains Malaysia. 3L: Language, Linguistics, Literature, 22(1), 127-140. https://doi.org/10.17576/3L2016-2201-10

Gilbert (2017). Quizlet in ESL Classroom: Enhancing Academic Vocabulary Acquisition of Japanese University Students. Teaching English With Technology Journal. [http://www.tewtjournal.org]

Günindi, Y. (2014). Usage of Mobile Technologies in Social Skills Development. Creative Education, 5, 1576-1584. http://dx.doi.org/10.4236/ce.2014.516174

Heba, S. (2015) What are the Advantages and Disadvantages of Telegram?. [ https://www.online sciences.cpm.what]

Hashim, H., Yunus, M.M., \& Embi, M. A. (2016). Pre-University English as Second Language (ESL) Learners' Attitude towards Mobile Learning. Creative Education, 7, 1147-1153.[ http://dx.doi.org/10.4236/ce.2016.78119]

Ibrahim, A. R., Yusoff, N. M. R. N., \& Kamarudin, M. Y. (2016). Mobile Learning Quality of Education and Increase in Student Discipline. Creative Education, 7, 555-560.[ http://dx.doi.org/10.4236/ce.2016.74057]

Kelsey (2017). The Effect of the Video Game Quizlet on the Acquisition of Science Vocabulary For Children With Learning Disabilities.

https://rdw.rowan.edu/cgi/viewcontent.cgi?article=3402\&context=etd]

Li (2017). Social Media in English Language Teaching and Learning, International Journal of Learning and Teaching (3), No. 2. [http://doi: 10.18178/ijlt.3.2.148-153]

Lie, W. W., and Yunus, M. M. (2018). Pen Pals Are Now In Your Finger Tips. A Global Collaboration Online Project To Develop Writing Skills. Creative Education,9, 2491-2504. [https://doi.org/10.4236/ce2018.915188]

Mao, C. (2014). Research on Undergraduate Students' Usage Satisfaction of Mobile Learning. Creative Education, 5, 614-618. [http://dx.doi.org/10.4236/ce.2014.58072]

Yunus, M.M and Suliman, A. (2014). Information \& Communication Technology (ICT) Tools in Teaching 
INTERNATIONAL JOURNAL OF ACADEMIC RESEARCH IN PROGRESSIVE EDUCATION AND

DEVELOPMENT

Vol. 7, No. 4, 2018, E-ISSN: $2226-6348 @ 2018$ HRMARS

and Learning Literature Component in Malaysian Secondary Schools. Asian Social Science,10(7), 136-152. [https://doi.org/10.5539/ass.v10n7p136]

Mona (2017). Using WhatsApp to Enhance Students' Learning of English Language "Experience to Share". Higher Education Studies; (7), 4.[http://doi.org/10.5539/hes.v7n4p74]

Nagayar, S., Abdul Aziz, A. \& Kanniah, M. N. (2015). Young Adult Literature and Higher-order Thinking Skills: $\quad$ A Confluence of Young Minds.(3),p.p 51-61. [ http://ijleal.ump.edu.my/ ]

Neil (2016). Attention span during lectures: 8 seconds, 10 minutes, or more? Adv Physiol Educ 40. [doi:10.1152/advan.00109.2016.]

Nestel, D., Gray, K., Ng, A., Mcgrail, M., Kotsanas, G., \& Villanueva, E. (2014). Mobile Learning in a Rural Medical School : Feasibility and Educational Benefits in Campus and Clinical Settings. Journal of Biomedical Education, 2014, 1-8. [https://doi.org/10.1155/2014/412786]

Sanosi, A. (2018). The Effect of Quizlet on Vocabulary Acquisition. Asian Journal of Education and eLearning.(6). 4 .

[https://www.researchgate.net/publication/327108959 The Effect of Quizlet on Vocabular y_Acquisition.]

Tung, C.A. and Chang, S.Y. (2009). Developing Critical Thinking Through Literature Reading. Feng Chia Journal of Humanities and Social Sciences. 287-217. [www.cocd.fcu.edu.tw/wSite/public/Attachment/f1262069682958.pdf.]

Xodanbande (2017): The effectiveness of social media network telegram in teaching English language pronunciation to Iranian EFL learners. Curriculum and Teaching Studies | Research Actic. 4: 134708. [https://doi.org/10.1080/2331186X.2017.1347081]

Zaki, A.A. and Yunus, M.M. (2015). Potential of Mobile Learning in Teaching of ESL Academic Writing. English Language Teaching,(8)6. [https://dx.doi.org/10.5539/elt.v8n6p11]

Zarei, R., Darani, L.H. and Ameri-Golestan, A. (2017). Effects of Telegram Application Advanced EFL Learners' Vocabulary Knowledge and Attitude. International Journal of Foreign Language Teaching \& Research.(5)20. [http://jfl.iaun.ac.ir/article_49624.html] 